ISSN: $1410-8917$

Jurnal Kimia

Sains \& Aplikasi
Jurnal Kimia Sains dan Aplikasi Journal of Scientific and Applied Chemistry

Journal homepage: http://ejournal.undip.ac.id/index.php/ksa

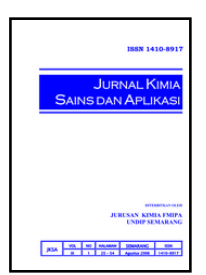

\title{
Modifikasi Silika Gel dari Abu Sekam Padi dengan $\gamma$-Glycidoxyopropyltrimethoxysilane dan Mercaptobenzothiazole untuk Adsorpsi Logam Kadmium(II)
}

\author{
Erna Kurnia Sari ${ }^{\mathrm{a}}$, Choiril Azmiyawati $^{\mathrm{a}^{*}}$, Taslimah $^{\mathrm{a}}$ \\ a Inorganic Chemistry Laboratory, Chemistry Department, Faculty of Sciences and Mathematics, Diponegoro University, Jalan Prof. \\ Soedarto, Tembalang, Semarang \\ * Corresponding author: choiril.azmiyawati@live.undip.ac.id
}

Article Info

Keywords:

modification, rice

husk ash, $\gamma-$ glycidoxypropyl trimethoxysilane

\begin{abstract}
A modified silica gel surface was modified from rice husk ash using Mercaptobenzothiazole (MBT) with an $\gamma$-glycidoxypropyltrimethoxysilane ( $\gamma$-GPTMS) as a liaison agent to adsorb $\mathrm{Cd}^{2+}$ in aqueous medium. The synthesis of mercaptobenzothiazole modified silica gel was conducted through several steps i.e. the manufacture of sodium silicate, the formation of silica gel, the binding of the epoxy group and the MBT on silica gel, and the adsorption of $\mathrm{Cd}^{2+}$ by silica gel. The silica gel modification was carried out with three variations of sequence of reagent addition in the mixed $\mathrm{pH}$ range of 5.5-5.8. In the first variation, the silica gel was added to the MBT ligand which already reacted with $\gamma$-GPTMS. In the second variation, the silica gel was added to the MBT ligand which previously reacted with $\gamma$-GPTMS. The third variation was performed by simultaneous mixing of sodium silicate solution with $6 \mathrm{M} \mathrm{HCl}$ and MBT ligands which before tied with $\gamma$-GPTMS. The results showed that the modified surface of silica gel synthesized from rice husk ash using Mercaptobenzothiazole with $\gamma$-glycidoxypropyltrimethoxysilane linking agent can be performed. It was also found that the second adsorbent had a higher adsorption capacity of $\mathrm{Cd}^{2+}$ than the first and third adsorbents which was $0.108 \mathrm{mmol} /$ gram.
\end{abstract}

\section{Abstrak}

Telah dilakukan modifikasi permukaan silika gel yang disintesis dari abu sekam padi menggunakan Mercaptobenzothiazole (MBT) dengan agen penghubung $\gamma^{-}$ glycidoxypropyltrimethoxysilane ( $\gamma$-GPTMS) untuk mengadsorpsi $\mathrm{Cd}^{2+}$ dalam medium air. Sintesis silika gel termodifikasi Mercaptobenzothiazole dilakukan melalui pembuatan natrium silikat, pembentukan silika gel, pengikatan gugus epoksi dan MBT pada silika gel, dan adsorbsi silika gel pada logam $\mathrm{Cd}^{2+}$. Modifikasi silika gel dilakukan dengan tiga variasi urutan penambahan reagen pada kisaran $\mathrm{pH}$ campuran 5,5-5,8. Variasi pertama, silika gel ditambahkan ligan MBT yang telah direaksikan dengan $\gamma$-GPTMS, variasi kedua silika gel ditambahkan dengan ligan MBT yang telah bereaksi dengan $\gamma$-GPTMS dan variasi ketiga dilakukan dengan pencampuran simultan larutan natrium silikat dengan HCl 6M dan ligan MBT yang telah diikatkan dengan $\gamma$-GPTMS. Hasil penelitian menunjukan bahwa modifikasi permukaan silika gel yang disintesis dari abu sekam padi menggunakan Mercaptobenzothiazole dengan agen penghubung $\gamma^{-}$ glycidoxypropyltrimethoxysilane dapat dilakukan. Diperoleh pula bahwa adsorben kedua memiliki kemampuan adsorpsi terhadap $\mathrm{Cd}^{2+}$ yang lebih besar daripada adsorben pertama dan ketiga, yaitu $0,108 \mathrm{mmol} /$ gram. 


\section{Pendahuluan}

Silika gel adalah material anorganik yang merupakan kelompok mineral dengan komponen utama berupa silikon dan oksigen yang tersusun dalam pola tiga dimensi. Silika gel banyak digunakan misalnya sebagai adsorben, karena silika gel memiliki gugus -OH atau gugus silanol, yang merupakan sisi aktif dari silika gel.

Banyak penelitian dilakukan untuk meningkatkan selektivitas silika gel, misalnya memodifikasi permukaan silika gel dengan menambahkan suatu bahan tertentu. Bahan yang ditambahkan biasanya bersifat spesifik terhadap logam. Beberapa penelitian yang berhubungan telah lama dirintis, misalnya penelitian mengenai impregnasi MBT yang telah dilakukan [1] pada silika gel untuk mengadsorpsi logam $\mathrm{Hg}$ (II) dalam medium air. Silika gel diimpregnasi dengan MBT menggunakan agen penghubung $\gamma^{-}$ aminopropyltriethoxysilane telah digunakan untuk adsorpsi dan prekonsentrasi (pemekatan) beberapa logam berat seperti Au (III), Pt (IV), dan Pd (II) [2]. Adanya penambahan MBT pada silika gel dapat meningkatkan daya adsorpsi dan dapat memisahkan $\mathrm{Au}$ (III), Pt (IV), dan Pd (II) dari ion logam dasarnya.

Berdasarkan beberapa penelitian yang telah ada, pada penelitian ini dilakukan penelitian tentang pengaruh penambahan Mercaptobenzothiazole (MBT) dengan menggunakan agen penghubung $\gamma^{-}$ glycidoxypropyltrimethoxysilane terhadap kemampuan adsorpsi silika gel dari abu sekam padi pada ion logam kadmium. Pemilihan Mercaptobenzothiazole sebagai bahan impregnan juga dilatarbelakangi oleh karakternya yang menyukai ikatan dengan suatu asam lunak. Berdasarkan konsep penggolongan asam-basa keras dan lunak [3], gugus SH pada MBT termasuk basa lunak karena memiliki ukuran relatif besar dan mudah terpolarisasi. Dari konsep HSAB (hard and soft acid and base), suatu spesies yang berfungsi sebagai basa lunak akan berikatan dengan asam lunak. Berdasarkan sifat tersebut, gugus SH yang diikatkan pada silika gel diharapkan dapat meningkatkan selektivitas adsorpsi silika gel terhadap logam lunak, khususnya logam kadmium (II).

\section{Metode}

\subsection{Preparasi Sampel}

Abu sekam padi diayak dengan ayakan 170 mesh, kemudian dicuci dengan $200 \mathrm{~mL}$ asam sulfat $5 \%$ dan disaring. Penambahan asam sulfat dilakukan dengan perbandingan 1gram sekam padi : $4 \mathrm{~mL}$ asam sulfat $5 \%$. Abu sekam padi selanjutnya dicuci kembali dengan akuades bertetes-tetes sampai filtrat yang terbentuk mempunyai $\mathrm{pH}$ yang netral, kemudian dioven pada temperatur $80^{\circ} \mathrm{C}$ selama 2 jam.

\subsection{Pembuatan Silika Gel}

\subsubsection{Pembuatan Natrium Silikat.}

Sebanyak 50 gram serbuk sekam ditambahkan ke dalam $1100 \mathrm{~mL}$ larutan $\mathrm{NaOH}$ 1,5 M dan didiamkan selama 24 jam. Dipanaskan dengan kompor listrik pada suhu $80^{\circ} \mathrm{C}$ selama 2 jam, kemudian didiamkan selama 24 jam. Selanjutnya campuran dipisahkan dengan kertas saring Whatman no. 42 sehingga diperoleh filtrat dan endapan. Endapan yang diperoleh dicuci kembali dengan akuades dan disaring. Filtrat hasil penyaringan pertama dan kedua dicampur sehingga diperoleh larutan natrium silikat. Larutan tersebut dianalisis dengan AAS untuk mengetahui kandungan silikanya.

\subsubsection{Preparasi Larutan $\gamma^{-}$ glycidoxypropyltrimethoxysilane $5 \%$.}

Sebanyak $1 \mathrm{~mL} \gamma^{-}$glycidoxypropyltrimethoxysilane ditambahkan dengan $20 \mathrm{~mL}$ etanol $96 \%$ p.a. Larutan sililasi yang terbentuk dijaga pada $\mathrm{pH}$ 5,5-5,8 dengan ditambahkan $\mathrm{KOH} 10^{-3} \mathrm{M}$. Ulangi untuk variasi $\gamma^{-}$ glycidoxypropyltrimethoxysilane $10 \%, 15 \%, 20 \%$, dan $25 \%$.

\subsubsection{Pembentukan Silika Gel.}

Sebanyak $25 \mathrm{~mL}$ natrium silikat masing-masing disiapkan pada lima gelas beaker. Pada masing-masing gelas beaker berturut-turut ditambahkan larutan $\mathrm{HCl} 6$ M sampai $\mathrm{pH}$ 5,5-5,8. Selanjutnya polimer asam silikat yang terbentuk ditambahkan dengan $\gamma^{-}$ glycidoxypropyltrimethoxysilane ( $\gamma$-GPTMS) 5\%, 10\%, $15 \%, 20 \%$, dan $25 \%$. Silika-GPTMS yang dihasilkan dikeringkan dalam desikator, kemudian dioven pada temperatur $40^{\circ} \mathrm{C}$ selama setengah jam. Hasilnya dianalisis dengan titrasi potensiometri untuk mengetahui variasi $\gamma$-glycidoxypropyltrimethoxysilane maksimal yang menghasilkan ikatan gugus epoksida maksimal.

\subsubsection{Penentuan Banyaknya Gugus Epoksi variasi 5\%.}

Banyaknya gugus epoksi yang terikat maka dilakukan dengan titrasi potensiometri. Sebanyak 0,2 gram silika gel-epoksi variasi $5 \%$ ditambahkan dengan $2 \mathrm{~mL}$ natrium tiosulfat $3 \mathrm{M}$, diaduk pada skala 5 selama 2 jam, kemudian dititrasi dengan larutan HCL 0,05 M. Ukur $\mathrm{pH}$ dan $\mathrm{HCl}$ yang ditambahkan. Pengulanga untuk silika gel-epoksi variasi 10\%, 15\%, 20\%, 25\%.

\subsubsection{Penentuan Banyaknya Gugus Epoksi Sebelum Penambahan MBT.}

Serbuk silika gel-epoksi hasil pengeringan sebelum ditambahkan MBT, ditentukan banyaknya gugus epoksi yang terikat dengan titrasi potensiometri. Serbuk silika gel-epoksi ditambah dengan natrium tiosulfat $3 \mathrm{M}$, diaduk pada skala 5 selama 2 jam, kemudian dititrasi dengan larutan HCL 0,05M. Ukur $\mathrm{pH}$ dan $\mathrm{HCl}$ yang ditambahkan.

\subsection{Modifikasi Silika Gel dengan Mercaptobenzothiazole (MBT)}

\subsubsection{Adsorben I}

Natrium silikat ditambahkan larutan $\mathrm{HCl} 6 \mathrm{M}$ sampai $\mathrm{pH}$ 5,5-5,8 sehingga terbentuk polimer asam silikat, selanjutnya polimer asam silikat ditambahkan dengan $\gamma$-glycidoxypropyltrimethoxysilane. Silika gelGPTMS ditambahkan dengan larutan Mercaptobenzothiazole $80 \%$, direfluks dengan suhu $110^{\circ} \mathrm{C}$ selama 30 menit kemudian didinginkan pada suhu 
kamar dan hasilnya disaring. Endapan yang diperoleh dicuci dengan akuades dan dengan etanol 96\% untuk melarutkan MBT yang berlebih, kemudian dikeringkan dengan dioven pada suhu $110{ }^{\circ} \mathrm{C}$ selama 1 jam. Dan hasilnya dianalisis dengan spektrofotometer FTIR.

\subsubsection{Adsorben II}

Natrium silikat ditambahkan larutan $\mathrm{HCl} \quad 6 \quad \mathrm{M}$ sampai $\mathrm{pH}$ 5,5-5,8 sehingga terbentuk polimer asam silikat, selanjutnya polimer asam silikat ditambahkan dengan $\gamma$-glycidoxypropyltrimethoxysilane yang telah direfluks dengan larutan Mercaptobenzothiazole $80 \%$ selama 30 menit pada suhu $110{ }^{\circ} \mathrm{C}$. Campuran yang diperoleh didinginkan pada suhu kamar dan hasilnya disaring. Endapan yang diperoleh dicuci dengan akuades dan dengan etanol 96\% untuk melarutkan MBT yang berlebih, kemudian dikeringkan dengan dioven pada suhu $110{ }^{\circ} \mathrm{C}$ selama 1 jam. Dan hasilnya dianalisis dengan spektrofotometer FTIR.

\subsubsection{Adsorben III}

Sementara pembentukan adsorben III dilakukan dengan menambahkan natrium silikat yang telah ditambah larutan $\mathrm{HCl} 6 \mathrm{M}$ dengan $\gamma^{-}$ glycidoxypropyltrimethoxysilane yang sebelumnya telah direaksikan dengan larutan Mercaptobenzothiazole $80 \%$. Campuran direfluks dengan suhu $110^{\circ} \mathrm{C}$ selama 30 menit. Campuran yang diperoleh didinginkan pada suhu kamar dan hasilnya disaring. Endapan yang diperoleh dicuci dengan akuades dan dengan etanol 96\% untuk melarutkan MBT yang berlebih, kemudian dikeringkan dengan dioven pada suhu $110^{\circ} \mathrm{C}$ selama 1 jam. Dan hasilnya dianalisis dengan spektrofotometer FTIR.

\subsection{Uji Adsorpsi silika gel terhadap Cd(II)}

\subsubsection{Adsorben I}

Sebanyak 10mL larutan $\mathrm{CdCl}_{2}$ ditambah dengan 0,05 gram adsorben I dan digojok dengan shaker selama 30 menit, kemudian didiamkan selama 24 jam untuk mencapai kesetimbangan. Campuran disaring dan filtrat yang dihasilkan dianalisis dengan AAS.

\subsubsection{Adsorben II}

Sebanyak 10mL larutan $\mathrm{CdCl}_{2}$ ditambah dengan 0,05gram adsorben II dan digojok dengan shaker selama 30 menit, kemudian didiamkan selama 24 jam untuk mencapai kesetimbangan. Campuran disaring dan filtrat yang dihasilkan dianalisis dengan AAS.

\subsubsection{Adsorben III}

Sebanyak 10mL larutan $\mathrm{CdCl}_{2}$ ditambah dengan 0,05gram adsorben III dan digojok dengan shaker selama 30 menit, kemudian didiamkan selama 24 jam untuk mencapai kesetimbangan. Campuran disaring dan filtrat yang dihasilkan dianalisis dengan AAS. Hasil adsorbsi dari adsorben I, adsorben II, dan adsorben III dibandingkan.

\section{Hasil dan Pembahasan}

\subsection{Pembentukan Natrium Silikat}

Natrium silikat dibuat dengan mereaksikan abu sekam dan natrium hidroksida, perbandingan mol adalah 1:2. Hasil yang diperoleh berupa larutan berwarna kecoklatan dengan sedikit endapan berwarna hitam kecoklatan dan diperoleh kadar Si dalam abu sekam padi sebesar 50,59\%.

\subsection{Modifikasi Silika Gel dengan Mercaptobenzothiazole (MBT)}

Modifikasi silika gel dengan MBT dilakukan dengan menggunakan agen penghubung yaitu $\gamma^{-}$ glycidoxypropyltrimethoxysilane ( $\gamma$-GPTMS), yang akan membuat silika gel tersebut memiliki gugus aktif berupa gugus - SH yang nantinya dapat berperan dalam proses adsorpsi.

\subsubsection{Pengikatan Agen Penghubung $\gamma^{-}$} glycidoxypropyltrimethoxysilane

Menurut [4]Chang (1976) reaksi antara gugus silanol dari silika gel dengan agen penghubung $\gamma^{-}$ glycidoxypropyltrimethoxysilane sebagai berikut.

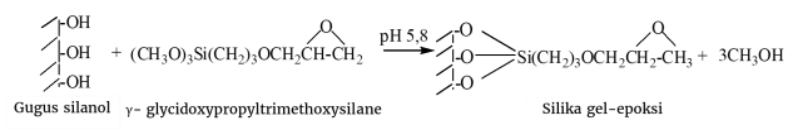

Titrasi potensiometri untuk menentukan banyaknya gugus epoksi yang terikat dilakukan dengan menambahkan natrium tiosulfat, reaksi yang terjadi dapat dituliskan sebagai berikut.

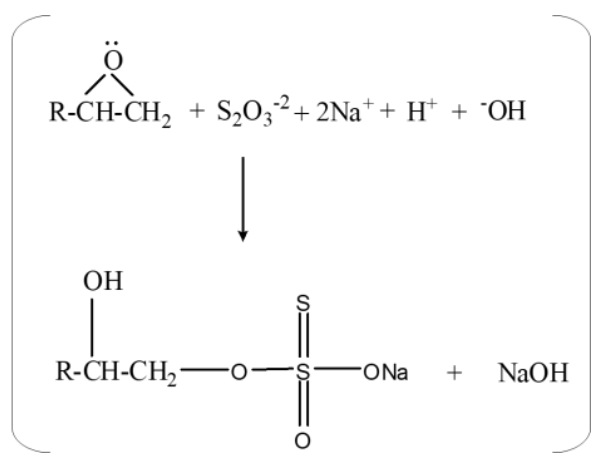

Tabel 1 Data hasil titrasi potensiometri untuk menentukan banyaknya gugus epoksi yang terikat (mmol)

\begin{tabular}{cc}
\hline $\begin{array}{c}\text { Variasi } \gamma- \\
\text { GPTMS }\end{array}$ & $\begin{array}{c}\text { Epoksi yang dihasilkan tiap } \\
0,2 \mathrm{~g}(\mathrm{mmol})\end{array}$ \\
\hline $5 \%$ & 0,087 \\
$10 \%$ & 0,16692 \\
$15 \%$ & 0,138595 \\
$20 \%$ & 0,1572 \\
$25 \%$ & 0,18759 \\
\hline
\end{tabular}

\subsubsection{Modifikasi Mercaptobenzothiazole (MBT)}

Reaksi antara silika gel yang telah terikat dengan agen penghubung $\gamma$ - glycidoxypropyltrimethoxysilane kemudian akan disubstitusi oleh MBT dapat diasumsikan ada 2 kemungkinan sebagai berikut: 
a

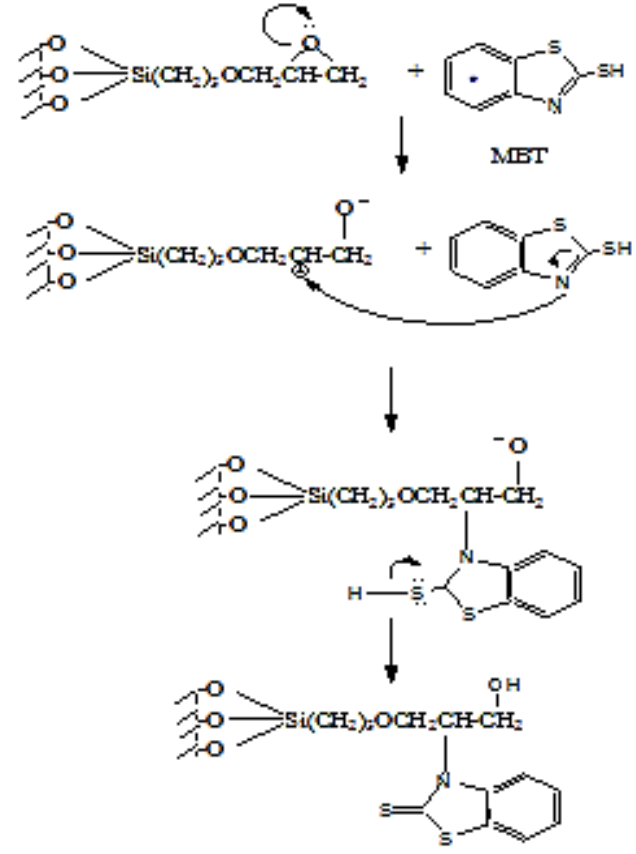

b.
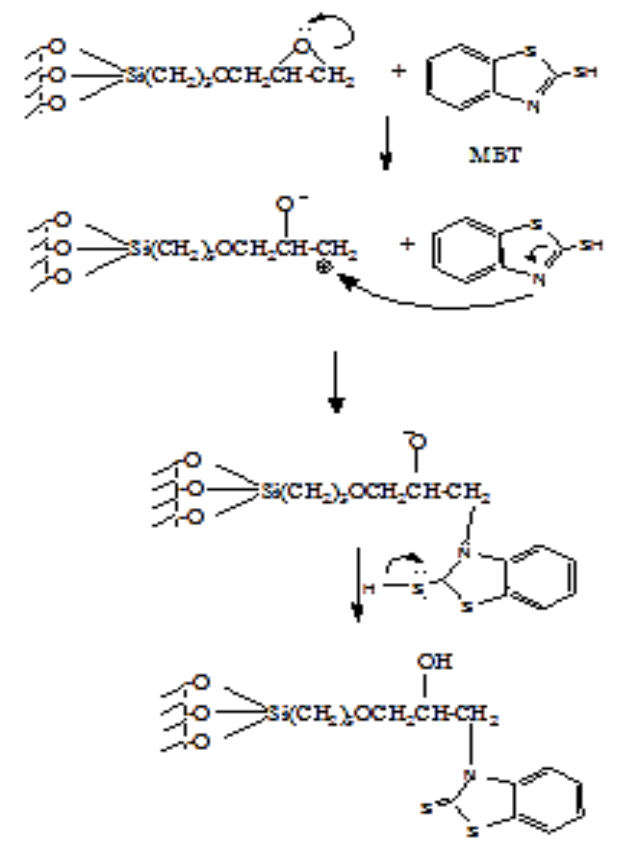

\subsection{Karakterisasi Silika Gel dengan Spektrofotometri Inframerah}

Perbandingan spektra ketiga adsorben pada Gambar 1 menunjukkan bahwa spektra SGM-2 dan SGM-3 memiliki bentuk spektra yang hampir mirip, namun pada spektra SGM-2 menunjukkan serapan dari vibrasi ulur ikatan -C-N lebih lebar dibandingkan SGM-3 serta memiliki beberapa puncak lain di sekitar panjang gelombang vibrasi ulur ikatan $-\mathrm{C}-\mathrm{N}$. Vibrasi ulur $-\mathrm{C}-\mathrm{N}$ pada spektra SGM-2 muncul didaerah serapan 1404,18 $\mathrm{cm}^{-1}$ sedangkan SGM-3 muncul disekitar $1388,75 \mathrm{~cm}^{-1}$, dari hal ini dapat diprediksi bahwa pada SGM-2 ikatan -C-N lebih kuat dibanding SGM-3 karena bilangan gelombang SGM-2 bergeser ke arah bilangan gelombang lebih besar sehingga energi menjadi lebih kuat.

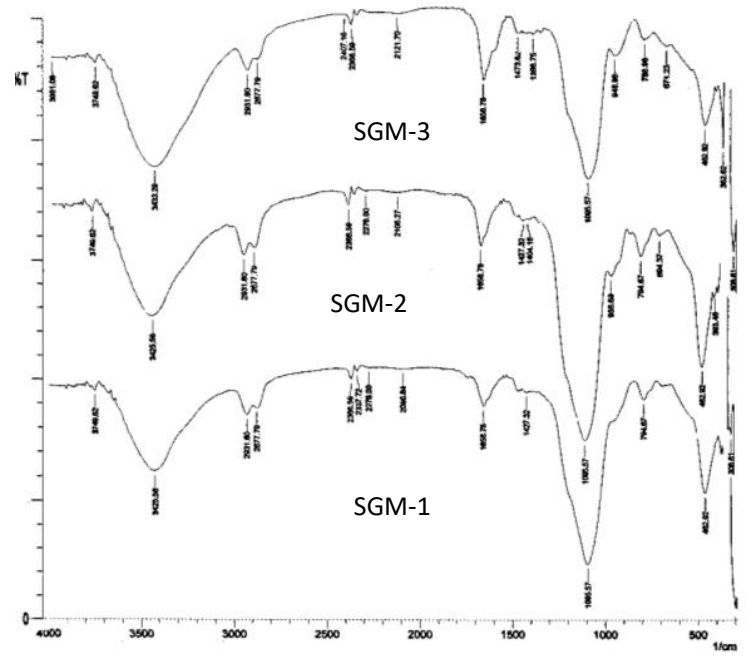

Gambar 1. Spektra infra-merah silika gel yang dimodifikasi dengan $\gamma$-GPTMS dan MBT variasi 1, 2, dan 3.

Gambar 2. memperlihatkan perbandingan antara adsorben 2 (SGM-2) dan adsorben 4 (SGM-4), spektra SGM-2 muncul daerah serapan sekitar $1400-1000 \mathrm{~cm}^{-1}$ yang menunjukkan vibrasi ulur ikatan -C-N, sedangkan pada SGM-4 tidak muncul, dan pada spektra SGM-4 muncul daerah serapan pada $848,88 \mathrm{~cm}^{-1}$ yang merupakan vibrasi ulur asimetri cincin epoksi. Hal ini membuktikan bahwa pada SGM-4 tidak terjadi interaksi antara ligan MBT dengan agen penghubung $\gamma$-GPTMS. Selain itu dari spektra SGM-2 pada daerah serapan 3400 $\mathrm{cm}^{-1}$ yang menunjukkan overtone dari $-\mathrm{OH}$ dan $-\mathrm{NH}$ terlihat puncak yang melebar, hal ini menunjukkan bahwa $-\mathrm{OH}$ yang muncul hanya sedikit. Sedangkan pada SGM-4 pada daerah serapan $3400 \mathrm{~cm}^{-1}$ terlihat puncak yang tajam, hal ini menunjukkan masih banyak gugus OH sehingga dapat disimpulkan bahwa pada SGM-4 tidak terjadi interaksi ligan Mercaptobenzothiazole (MBT) dengan agen penhubung $\gamma$ - glycidoxypropyltrimethoxy silane $(\gamma$-GPTMS).

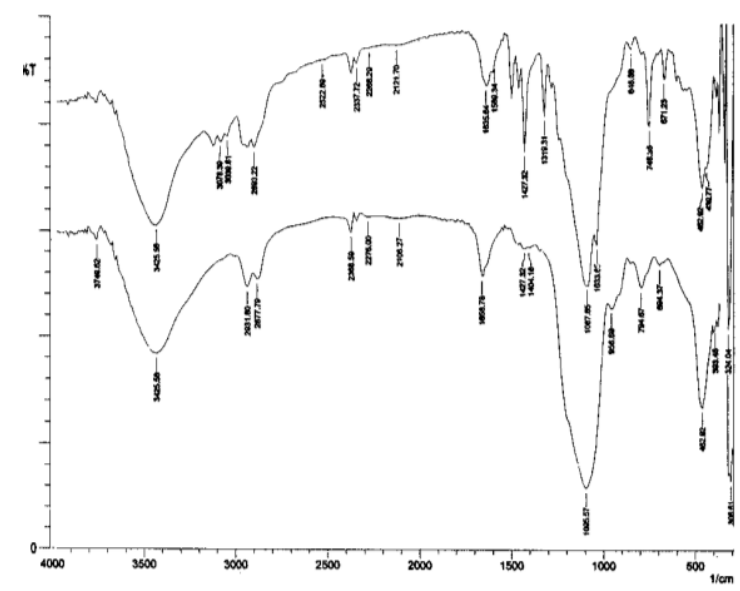

Gambar 2. Spektra infra-merah SGM-2 dan SGM-4

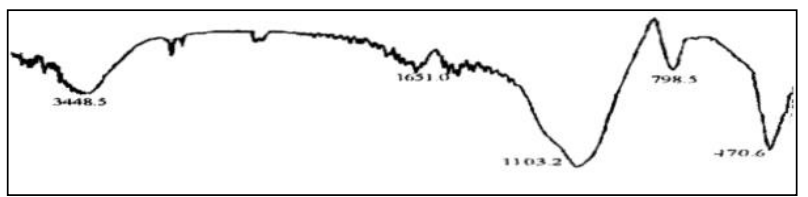




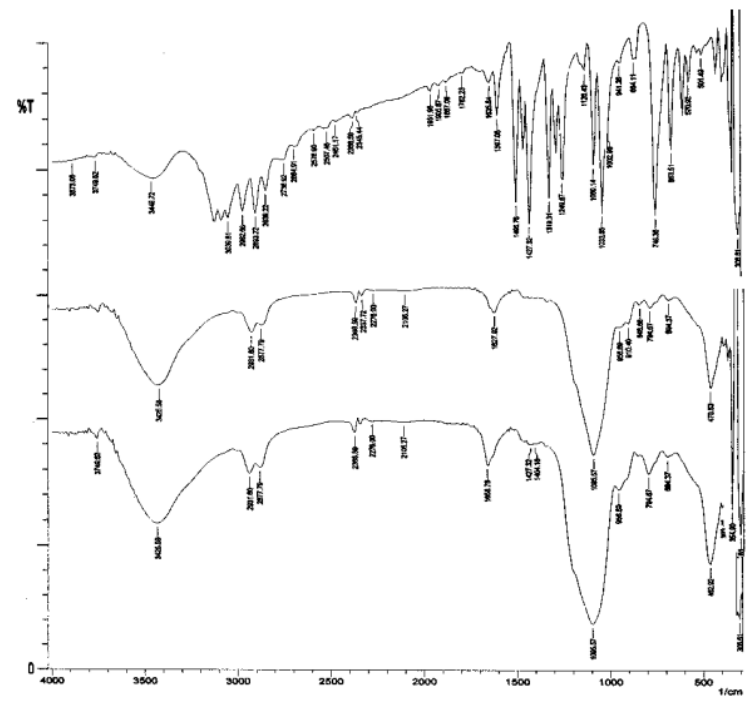

Gambar 3. Spektra infra-merah abu sekam padi, SGM2, SG 25\%, dan MBT

Spektra SGM-2 dibandingkan dengan spektra silika gel dari abu sekam padi [5]si(Retno,2001) menunjukkan beberapa serapan yang sama dengan silika gel dari abu sekam padi yaitu pada daerah serapan disekitar 3400 $\mathrm{cm}^{-1}$ yang merupakan vibrasi ulur $-\mathrm{OH}$ dari $\mathrm{Si}-\mathrm{OH}$ yang menunjukkan adanya gugus silanol. Daerah serapan $1103,2 \mathrm{~cm}^{-1}$ yang menunjukan vibrasi ulur asimetri $\mathrm{Si}-\mathrm{O}$ dari Si-O-Si , daerah $798,5 \mathrm{~cm}^{-1}$ merupakan vibrasi ulur simetri $\mathrm{Si}-\mathrm{O}$ dari $\mathrm{Si}-\mathrm{O}-\mathrm{Si}$ yang menunjukan menunjukkan adanya gugus siloksan, dan daerah $470,6 \mathrm{~cm}^{-1}$ yang menunjukkan vibrasi tekuk Si-O-Si.

SGM-2 memiliki beberapa puncak serapan sekitar $1400-1000 \mathrm{~cm}^{-1}$ yang menunjukkan vibrasi ulur ikatan $\mathrm{C}-\mathrm{N}$, serapan ini menunjukkan adanya MBT yang bereaksi dengan silika gel tersebut. Spektra SG $25 \%$ muncul daerah serapan $1627,92 \mathrm{~cm}^{-1}$ yang merupakan pita talunan fermi (nada lipat dari regangan cincin epoksi) dan pada daerah $848,88 \mathrm{~cm}^{-1}$ yang merupakan vibrasi ulur asimetri cincin epoksi, sedangkan pada SGM-2 tidak muncul, hal ini menunjukkan bahwa pada SGM-2 gugus epoksi telah berubah.

Spektra pada SGM-2, muncul daerah serapan $1658,78 \mathrm{~cm}^{-1}$ yang menunjukkan adanya vibrasi ulur C$\mathrm{N}$ dari amina aromatik tersier, sedangkan pada MBT pola serapan ini juga muncul didaerah $1635,64 \mathrm{~cm}^{-1}$, adanya pergeseran daerah serapan yang bergeser ke arah bilangan gelombang yang lebih besar akan menyebabkan energinya juga besar. Hal ini menunjukan bahwa gugus $\mathrm{N}$ dari MBT itu terikat lebih kuat pada $\mathrm{C}$ dari SGM-2.

\subsection{Uji adsorpsi silika gel terhadap Cd(II)}

Uji adsorpsi silika gel terhadap Cd(II) 0,5649 mmol/L dilakukan untuk mengetahui kemampuan silika gel yang dihasilkan dalam mengadsorpsi logam $\mathrm{Cd}(\mathrm{II})$, uji adsorpsi silika gel ini di analisa dengan menggunakan Spektrofotometer Serapan Atom (SSA).
Tabel 2. Data hasil analisis AAS dari adsorpsi silika gel terhadap Cd(II) 0,5649mmol/L

\begin{tabular}{cccc}
\hline $\begin{array}{c}\text { Kode } \\
\text { Silika } \\
\text { Gel }\end{array}$ & $\begin{array}{c}\text { Konsentrasi } \\
\text { Cd awal } \\
(\mathrm{mmol} / \mathrm{L})\end{array}$ & $\begin{array}{c}\text { Konsentrasi } \\
\text { Cd(II) yang } \\
\text { teradsorpsi } \\
(\mathrm{mmol} / \mathrm{L})\end{array}$ & $\begin{array}{c}\text { Daya } \\
\text { Adsorpsi } \\
(\%)\end{array}$ \\
\hline SGM-1 & 0,5649 & 0,47502 & $87,12 \%$ \\
SGM-2 & 0,5649 & 0,53786 & $98,64 \%$ \\
SGM-3 & 0,5649 & 0,50273 & $95,50 \%$ \\
\hline
\end{tabular}

Tabel 2. menunjukkan bahwa konsentrasi Cd(II) yang teradsorpsi oleh silika gel kedua memberikan hasil adsorbsi lebih efektif dari pada silika gel yang lain, dimana variasi pengikatan adsorben kedua dilakukan dengan mengikatkan ligan MBT dengan $\gamma$-GPTMS $25 \%$ terlebih dahulu kemudian direaksikan dengan silika gel. Banyaknya jumlah logam Cd(II) yang teradsorpsi adsorben kedua untuk rasio perbandingan 0,05gram adsorben dalam 10mL larutan, yaitu sebesar $0,53786 \mathrm{mmol} / \mathrm{L}$ atau sebesar $0,10757 \mathrm{mmol} / \mathrm{g}$ dengan daya adsorpsi $98,64 \%$.

\section{Kesimpulan}

Silika gel termodifikasi $\gamma$-GPTMS-MBT telah berhasil disintesis dari abu sekam padi. Silika gel termodifikasi $\gamma$-GPTMS-MBT dapat mengadsorpsi logam Cd(II) dan kemampuan adsorpsi optimumnya dicapai oleh adsorben variasi pengikatan kedua, yaitu sebesar $0,10757 \mathrm{mmol} / \mathrm{g}$.

\section{Daftar Pustaka}

[1] Kikuo Terada, Ken Matsumoto, Hitoshi Kimura, Sorption of copper (II) by some complexing agents loaded on various supports, Analytica chimica acta, 153, (1983) 237-247

[2] Newton L. Dias Filho, Yoshitaka Gushikem, Wagner L. Polito, 2-Mercaptobenzothiazole clay as matrix for sorption and preconcentration of some heavy metals from aqueous solution, Analytica Chimica Acta, 306, 1, (1995) 167-172 http://dx.doi.org/10.1016/0003-2670(94)00673-A

[3] T Saito, Text Book of Inorganic Chemistry, Hard and Soft Acid and Bases, Konagawa University, Japan, 52, 53, (2004)

[4] Shung Ho Chang, Karen M Gooding, Fred E Regnier, Use of oxiranes in the preparation of bonded phase supports, Journal of Chromatography A, 120, 2, (1976) 321-333

[5] A Retno, Sintesis Silika Gel dari Abu Sekam Padi dengan Asam Klorida, in: Jurusan Kimia, Universitas Diponegoro, Semarang, 2001. 